\title{
Muurahaishapon neutraloinnin vaikutus tuoreen ja esikuivatun säilörehun laatuun
}

\author{
Eeva Saarisalo ${ }^{1)}$ ja Seija Jaakkola ${ }^{2)}$ \\ ${ }^{1)}$ MTT, Eläinravitsemus, 31600 Jokioinen (eeva.saarisalo@mtt.fi) \\ ${ }^{2)}$ HY, Kotieläintieteen laitos, Pl 28, 00014 Helsingin yliopisto (seija.jaakkola@helsinki.fi)
}

\section{Tiivistelmä}

Säilörehun hyvä laatu on tärkeää korkealuokkaisen maidon tuottamiseksi. Säilönnässä onnistuminen on oleellista myös taloudelliselta kannalta, sillä huonossa säilörehussa hukataan nurmen viljelyyn käytetyt panokset ja tilalle on hankittava muuta rehua. Säilöntäaineen käyttö varmistaa rehun hyvän käymislaadun. Perinteisesti hyväksi todetun muurahaishapon $(\mathrm{MH})$ haittana on syövyttävyys. Se on vähentänyt happosäilöntäaineiden käyttöä erityisesti yleistyvässä urakoinnissa. Syövyttävyyttä voidaan vähentää neutraloimalla muurahaishappoa ammoniakilla eli korvaamalla osa muurahaishaposta sen suolalla ammoniumformiaatilla (AF). Ei kuitenkaan ole ollut tarkkaa tietämystä siitä, miten tämä neutralointi vaikuttaa säilöntäprosessiin eri kuiva-ainepitoisuuksissa.

Laboratorio-mittakaavan kokeissa tutkittiin AF:n vaikutusta säilönnän aikana tuoreessa (ka 210 $\mathrm{g} / \mathrm{kg}$ ) ja esikuivatussa (ka $406 \mathrm{~g} / \mathrm{kg}$ ) nurmirehussa. Käsittelyjä oli seitsemän: Painorehu (PR) ilman säilöntäainetta sekä AF:MH-osuudet 0:85 (AF0), 5:80 (AF5), 10:75 (AF10), 20:65 (AF20), 30:55 (AF30) ja 40:45 (AF40). Lisäksi liuoksissa oli $15 \%$ vettä. Annostus oli $6 \mathrm{~g} / \mathrm{kg}$ rehua eli $5 \mathrm{l} / \mathrm{t}$ rehua. Säilönnänaikaisia muutoksia seurattiin avaamalla kaksi siiloa käsittelyä kohti 1,3, 7, 21 ja 97 päivää säilönnästä.

AF:n lisääntyvä osuus näkyi ensimmäisen viikon aikana hidastuvana $\mathrm{pH}: n$ laskuna, mutta silti kaikissa AF-käsittelyissä pH laski selvästi painorehua nopeammin. Tuoreessa rehussa painorehun $\mathrm{pH}$ laski AF-rehujen $\mathrm{pH}: t a$ alemmas kolmen ja seitsemän päivän välillä säilönnästä, kun esikuivatussa painorehun pH oli säilönnän loppuun asti (97 pv) AF-rehujen pH:ta korkeampi. Suurin AF-määrä (AF40) vähensi muurahaishapon käymistä rajoittavaa vaikutusta erityisesti tuoreessa rehussa, mutta siinäkin käyminen oli rajoittaneempaa kuin painorehussa (Taulukko 1). Muurahaishapon neutralointi ei heikentänyt sen säilöntätehoa, kun käytettiin suositusten mukaista annostusta 5 1/t.

Taulukko 1 Rehujen käymislaatu säilönnän lopussa. Ammoniumtyppi $\left(\mathrm{NH}_{3}-\mathrm{N}\right)$ : a analysoitu, b analysoitu säilöntäaineessa lisätty.

\begin{tabular}{|c|c|c|c|c|c|c|c|c|c|c|c|c|c|}
\hline \multirow[b]{2}{*}{ TUORE } & \multicolumn{7}{|c|}{ Säilöntäaine } & \multicolumn{6}{|c|}{ Tilastollinen merkitsevyys } \\
\hline & PR & AFO & AF5 & AF10 & AF20 & AF30 & AF40 & SEM & $\begin{array}{c}\text { PR } v s \\
\text { AF }\end{array}$ & AF lin & $\begin{array}{c}\text { AF } \\
\text { quad }\end{array}$ & $\begin{array}{c}\text { AF } \\
\text { cubic }\end{array}$ & $\begin{array}{l}\text { AF } \\
\text { quar }\end{array}$ \\
\hline $\mathrm{pH}$ & 4,03 & 4,07 & 4,11 & 4,00 & 4,04 & 4,08 & 4,16 & 0,008 & $* * *$ & $* * *$ & $* * *$ & $*$ & \\
\hline Sokeri g/kg ka & 17 & 25 & 23 & 27 & 26 & 27 & 21 & 1,0 & $* * *$ & $*$ & $* *$ & & \\
\hline Maitohappo g/kg ka & 121 & 71 & 73 & 66 & 71 & 71 & 91 & 1,1 & $* * *$ & $* * *$ & $* * *$ & $*$ & $* *$ \\
\hline VFA g/kg ka & 35 & 25 & 33 & 24 & 25 & 24 & 34 & 4,4 & & & & & \\
\hline $\mathrm{NH}_{3}-\mathrm{N}$ g/kg N a) & 61 & 29 & 54 & 35 & 48 & 64 & 95 & 1,1 & $* * *$ & $* * *$ & $* * *$ & $*$ & \\
\hline $\mathrm{NH}_{3}-\mathrm{N}$ g/kg N b) & 61 & 29 & 43 & 15 & 7 & 4 & 11 & 1,5 & $* * *$ & $* * *$ & $* * *$ & & \\
\hline \multicolumn{14}{|l|}{ ESIKUIVATTU } \\
\hline $\mathrm{pH}$ & 4,46 & 4,20 & 4,23 & 4,27 & 4,25 & 4,23 & 4,27 & 0,015 & $* * *$ & & & $*$ & \\
\hline Sokeri g/kg ka & 15 & 32 & 34 & 39 & 35 & 22 & 19 & 3,9 & $* *$ & $*$ & & & \\
\hline Maitohappo g/kg ka & 69 & 54 & 52 & 50 & 56 & 57 & 62 & 2,9 & $* *$ & $*$ & & & \\
\hline VFA g/kg ka & 17 & 16 & 16 & 16 & 16 & 17 & 18 & 0,5 & & & & & \\
\hline $\mathrm{NH}_{3}-\mathrm{N} \mathrm{g} / \mathrm{kg} \mathrm{N}$ a) & 29 & 17 & 20 & 24 & 33 & 43 & 49 & 1,4 & & $* * *$ & & & \\
\hline $\mathrm{NH}_{3}-\mathrm{N}$ g/kg N b) & 29 & 17 & 15 & 15 & 13 & 13 & 9 & 1,6 & $* * *$ & $* *$ & & & \\
\hline
\end{tabular}

\section{Asiasanat}

Nurmirehu, säilöntä, säilörehu, muurahaishappo, ammoniumformiaatti, esikuivatus, $\mathrm{pH}$. 


\section{Johdanto}

Happosäilöntäaineiden syövyttävyyden vähentäminen ja käyttöturvallisuuden parantaminen edellyttää valmisteiden neutralointiasteen lisäämistä. Tavoitteena ovat säilöntäaineet, joiden ominaisuuksissa yhdistyvät sekä käyttöturvallisuus että säilöntäteho. Muurahaishapon (MH) neutralointi voidaan tehdä ammoniakilla, jolloin syntyy ammoniumformiaattia (AF). Vapaan muurahaishapon määrä vähenee vastaavasti, samoin kuin välitön happamoittava vaikutus. Ammoniumformiaatin merkityksestä rehun säilönnässä ei ole selvää käsitystä. Märässä rehussa hapon määrä vaikuttaa selvästi käymisen voimakkuuteen (Jaakkola 1993), kun taas esikuivatussa rehussa veden puute sinänsä rajoittaa käymistä. Tutkimuksessa selvitettiin happopohjaisen säilöntäaineen osittaisen neutraloinnin eli ammoniumformiaatin määrän ja samalla $\mathrm{AF} / \mathrm{MH}$-suhteen vaikutusta tuoreen ja pitkälle esikuivatun rehun säilönnässä.

\section{Aineisto ja menetelmät}

Raaka-aine ja käsittelyt. Koerehut tehtiin kahdessa eri kuiva-ainepitoisuudessa timotei-nurminatanurmen ensimmäisestä sadosta MTT Jokioisilla vuonna 2003. Nurmi niitettiin niittomurskaimella, minkä jälkeen tuoreen rehun (kuiva-ainetavoite $200 \mathrm{~g} / \mathrm{kg}$ ) raaka-aine oli karholla $1,5 \mathrm{t}$ ja esikuivatun (kuiva-ainetavoite $400 \mathrm{~g} / \mathrm{kg}$ ) $21 \mathrm{t}$ ennen korjuuta ja silppuamista näytesilppurilla.

Säilöntäainekäsittelyitä oli yhteensä 7, joista yksi oli painorehu (PR, ei säilöntäainetta). Muurahaishappoon perustuvissa koeliuoksissa lisättiin asteittain AF:n osuutta seuraavasti: 0, 5, 10, 20, 30 ja $40 \%$. Vastaavasti MH:n (100 \%:na ilmaistu) osuudet olivat 85, 80, 75, 65, 55 ja $45 \%$. Veden osuus oli kaikissa $15 \%$. Säilöntäainetta levitettiin sumutuspullolla $6 \mathrm{~g} / \mathrm{kg}$ laimentamattomana $2 \mathrm{~kg}$ ruohoerään.

Rehut tehtiin $120 \mathrm{ml}: n$ minisiiloihin, jotka varastoitiin huoneenlämpötilassa pimeässä. Märempää rehua säilöttiin $85 \mathrm{~g} /$ siilo ja kuivempaa $70 \mathrm{~g} /$ siilo. Säilöntäaikoja oli yhteensä 5: 1, 3, 7, 21 ja 97 vrk, joille kaikille tehtiin kaksi rinnakkaispulloa eli yhteensä $70 \mathrm{kpl} \mathrm{molemmissa} \mathrm{kuiva-aineluokissa.}$

Siiloista mitattiin säilönnän aikainen kaasunmuodostus, joka kuvaa käymisen nopeutta ja määrää eli käymisestä johtuvaa säilöntätappiota. Ensimmäinen mittauskerta oli rehuntekopäivänä. Säilönnän alussa mittaus tehtiin kahdesti päivässä ja mittauskertoja harvennettiin kaasunmuodostuksen mukaan.

Näytteenotto ja analyysit. Koko raaka-aine-erästä otettiin näyte juuri ennen rehun tekoa punnittaessa ruohoa käsittelyjä varten. Näytteestä tehtiin primäärinen kuiva-aine, kuivattiin analyysinäyte sekä pakastettiin erikoisanalyysi- ja puskurikapasiteettinäyte. Näytteistä analysoitiin sekundäärinen kuiva-aine, tuhka, raakavalkuainen (Leco), neutraalidetergenttikuitu (NDF), pelkistävät sokerit, liukoinen N, puskurikapasiteetti ja in vitro -sellulaasisulavuus.

Säilöntäaineella käsitellystä ruohosta otettiin näytteeksi siilojen täytöstä yli jäänyt rehu. Näytteestä tehtiin primäärinen kuiva-aine, $\mathrm{pH}$ sekä pakastettiin erikoisanalyysinäyte. Näytteistä määritettiin myöhemmin puskurikapasiteetti ja muurahaishappo.

Siilot avattiin 1, 3, 7, 21 ja 97 vuorokauden kuluttua säilönnästä. Jokaisella kerralla avattiin kaksi siiloa/käsittely. Siilo punnittiin, tyhjennettiin ja koko sisältö otettiin näytteeksi. Näytteistä määritettiin heti kuiva-aine ja typpi (tuoreesta) ja pakastettiin erikoisanalyysinäyte. Erikoisanalyysinäytteestä määritettiin $\mathrm{pH}$, muurahaishappo, maitohappo, VFA, pelkistävät sokerit, etanoli ja ammonium N.

Tilastollinen testaus. Lopputilanteen (97 vuorokautta) koostumustulokset testattiin SAS-ohjelman GLMproseduurilla. Käsittelyn vaikutus jaettiin edelleen ortogonaalisiin kontrasteihin: painorehu vs. muut, säilöntäaineen neutraloinnin (ammoniumformiaatin osuus) lineaarinen, toisen, kolmannen ja neljännen asteen käyräviivainen vaikutus (näissä AF5 ei mukana).

\section{Tulokset ja niiden tarkastelu}

Raaka-aineen kuiva-ainepitoisuus oli tuoreessa rehussa $210 \mathrm{~g} / \mathrm{kg}$ ja esikuivatussa $406 \mathrm{~g} / \mathrm{kg}$. Sulavuus oli molemmissa erissä erittäin hyvä (D-arvo keskimäärin $738 \mathrm{~g} / \mathrm{kg}$ ). Raakavalkuaispitoisuus oli tuoreessa/ esikuivatussa raaka-aineessa $172 / 180 \mathrm{~g} / \mathrm{kg} \mathrm{ka}$, sokeripitoisuus $151 / 137 \mathrm{~g} / \mathrm{kg} \mathrm{ka}$, puskurikapasiteetti $509 / 529 \mathrm{mekv} / \mathrm{kg}$ ka sekä tuhka 73/82 g/kg ka. Suuri valkuaispitoisuus ja puskurikapasiteetti vaikeuttavat säilöntää, mutta toisaalta säilöttävyyttä edistävän sokerin pitoisuus oli kohtuullisen korkea.

\section{Tuore rehu}

Kaasunmuodostus. Painorehu ja AF40-rehu erottuivat muista rehuista sekä säilönnän alkuvaiheessa kaasuntuotannon nopeudessa että kaasun kokonaismäärässä koko säilöntäajalla (Kuvio 1a ja Taulukko 2). Myös AF5:n lopullinen kaasumäärä oli muista happorehuista poikkeava. Näiden kolmen rehun toinen rin- 
nakkaissiiloista stabiloitui, mutta toisessa siilossa kaasunmuodostus jatkui kokeen loppuun asti. Muissa rehuissa kaasunmuodostus loppui lähes kokonaan noin neljän viikon kuluttua säilönnästä. AF5 ja AF40 rehujen selvästi tavoitetta pienempi muurahaishappopitoisuus voi olla syy tulokseen.

Kaasuntuotanto alkoi nopeimmin painorehusta ja hitaimmin AF10 ja AF20 -rehuista. Kaasun kokonaismäärä oli painorehussa 20,5 ml/g ka, AF5-rehussa $20,7 \mathrm{ml} / \mathrm{g} \mathrm{ka}$ ja AF40-rehussa 21,4 ml/g ka. Muiden rehujen keskiarvo oli $16,7 \mathrm{ml} / \mathrm{g}$ ka ja niissäkin käsittelyjen väliset erot olivat pieniä. Käsittelyiden vaikutus kaasunmuodostukseen ei ollut tilastollisesti merkitsevä. Painomuutoksen perusteella neutralointiasteen lisääminen suurensi lineaarisesti säilönnän aikaista painohävikkiä (lin $\mathrm{P}<0,05$ ).

Käymislaatu. Kaikki tuoreet rehut, painorehu mukaan lukien, olivat kokeen lopussa laadultaan hyviä eli $\mathrm{pH}$ oli kuiva-ainepitoisuuteen nähden riittävän alhaalla eikä rehuissa esiintynyt virhekäymistä tai liiallista valkuaisen hajoamista. Etikkahapon määrä, keskimäärin 28,1 g/kg ka, oli kuitenkin melko korkea.

Heti säilönnän jälkeen painorehun $\mathrm{pH}$ oli muita rehuja korkeampi kolmanteen päivään asti (Kuvio 2). Seitsemäntenä päivänä painorehun $\mathrm{pH}$ oli laskenut kaikkien muiden rehujen $\mathrm{pH}: n$ alapuolelle. Säilöntäajan lopussa painorehun pH-arvo $(4,03)$ oli muita rehuja keskimäärin alempi $(4,08)(\mathrm{P}<0,001)$, mutta numeerinen ero oli hyvin pieni.

Painorehu poikkesi happorehuista selvästi maitohappokäymisen voimakkuudessa. Säilöntäajan lopussa painorehun sokeripitoisuus oli hieman pienempi $(17,0$ vs. $24,9 \mathrm{~g} / \mathrm{kg} \mathrm{ka})(\mathrm{P}<0,001)$ ja maitohappopitoisuus selvästi suurempi $(121,2$ vs. $73,8 \mathrm{~g} / \mathrm{kg} \mathrm{ka})(\mathrm{P}<0,001)$ kuin happorehuissa keskimäärin. Raakaaineen suuri sokeripitoisuus teki mahdolliseksi painorehun voimakkaan maitohappotuotannon. Haihtuvissa rasvahapoissa merkitsevä ero oli vain voihappopitoisuudessa, joka oli painorehussa muita rehuja suurempi $(\mathrm{P}<0,05)$ vaikkakin numeerisesti hyvin pieni 0,3 vs. 0,2 .

Säilönnän ensimmäisten päivien aikana AF40-rehun pH oli muita happorehuja korkeampi ja AF20 ja AF30-rehujen pH:t olivat kaikkein alimmat. Kolme viikkoa säilönnästä happorehujen välillä ei enää ollut eroa $\mathrm{pH}$ :ssa.

Säilöntäajan lopussa korjaamaton ammoniumtypen osuus oli painorehussa suurempi kuin rehuissa AF0-AF20 ja pienempi kuin rehuissa AF30-AF40. Sen sijaan säilöntäaineessa lisätyn ammoniumtypen perusteella korjattu pitoisuus oli painorehussa selvästi suurempi kuin kaikissa happorehuissa $(\mathrm{P}<0,001)$.

Neutralointiasteen lisäys ei vaikuttanut lineaarisesti käymisparametreihin säilöntäajan lopussa. Käyräviivaisuutta aiheuttivat lähinnä AF5 ja AF40 käsittelyt eli tulos vastasi kaasuntuotantotulosta. Näissä rehuissa oli hieman vähemmän sokeria ja AF40-rehussa enemmän maitohappoa kuin muissa happorehuissa. Lisäksi näissä rehuissa muodostui enemmän ammoniakkia. Etikkahapossa ja VFA:n kokonaismäärässä ei ollut merkitseviä eroja käsittelyiden välillä, mutta määrät olivat suurempia AF5- ja AF40-rehuissa kuin muissa happorehuissa ja samaa tasoa kuin painorehussa.

AF40-rehussa maitohapon osuus hapoista oli 72,8 ja maitohappo/etikkahappo - suhde 2,9 eli samaa tasoa kuin muissa happorehuissa, joissa keskiarvot olivat 72,9 ja 2,8. Sen sijaan AF5-rehussa maitohapon osuus $(69,2)$ oli muita rehuja pienempi. Tämän perusteella AF5:n poikkeavuus liittyi enemmän sekakäymiseen kuin AF40-rehussa, jossa sen sijaan oli kyse voimakkaammasta käymisestä, jonka korkea säilöntäaineen neutralointiaste ilmeisesti salli.

Ammoniumtypen korjaamaton pitoisuus lisääntyi AF:n osuuden kasvaessa (lin, quad, $\mathrm{P}<0,001$ ). Tämä selittyy pääosin säilöntäaineessa lisätyllä ammoniakilla, sillä korjattu pitoisuus puolestaan pieneni AF:n osuuden kasvaessa (lin, quad, $\mathrm{P}<0,001$ ). Edellä mainittu muita voimakkaampi käyminen AF5- ja AF40-rehuissa näkyi myös muita suurempana korjatun ammoniumtypen määränä.

\section{Esikuivattu rehu}

Kaasunmuodostus. Painorehun kaasunmuodostus alkoi nopeammin ja kaasun määrä oli suurempi $(\mathrm{P}<0,001)$ kuin muissa rehuissa (Taulukko 3 ja Kuvio 1b). Happorehuista erottuivat AF30 ja AF40 sekä nopeamman alun että suuremman määrän perusteella. Muiden happorehujen väliset keskinäiset erot olivat sen sijaan hyvin pieniä. Neutralointi kuitenkin lisäsi käyräviivaisesti kaasun määrää (lin $\mathrm{P}<0,001$, quadr ja cubic $\mathrm{P}<0,01)$. Painomuutoksen perusteella neutralointi lisäsi lineaarisesti painohävikkiä $(\mathrm{P}<0,001)$. Toisin kuin tuoreessa rehussa, kaasuntuotanto ei loppunut yhdessäkään rehussa vaan se jatkui hitaasti säilöntäajan loppuun asti. Rehut eivät tämän perusteella stabiloituneet 97 vuorokauden aikana. Tällöin jälkipilaantumisriski kasvaa, mutta sitä ei mitattu tässä kokeessa. 
Käymislaatu. Myös kaikki esikuivatut rehut olivat laadultaan hyviä eli pH oli kuiva-ainepitoisuuteen nähden riittävän alhaalla, eikä rehuissa esiintynyt virhekäymistä tai liiallista valkuaisen hajoamista. Etikkahapon määrä oli näissäkin rehuissa melko korkea (keskimäärin $16,3 \mathrm{~g} / \mathrm{kg} \mathrm{ka}$ ).

Painorehun $\mathrm{pH}$ oli heti säilönnän alussa ja myös koko säilöntäajan selvästi korkeampi kuin happorehujen (Kuvio 2). Säilöntäajan lopussa painorehun pH oli 0,22-yksikköä korkeampi kuin happorehujen $(4,24)(\mathrm{P}<0,001)$.

Toisin kuin tuoreessa rehussa käyminen ja muutokset sokeri- ja maitohappopitoisuuksissa jatkuivat esikuivatussa rehussa myös kolmen viikon jälkeen. Kaasunmuodostuksen perusteella käyminen jatkui tasaisesti noin 50 vuorokauden ajan, jonka jälkeen se hidastui jonkin verran. AF30 ja AF40 rehuissa käyminen oli 7-21 päivän välillä nopeampaa kuin kaikissa muissa rehuissa. Tämän vuoksi näiden rehujen $\mathrm{pH}$ laski kyseisenä aikana nopeammin kuin muiden happorehujen $\mathrm{pH}$.

Säilöntäajan lopussa painorehu erosi säilöntäaineella käsitellyistä rehuista käymisasteen perusteella eli sen sokeripitoisuus oli pienempi $(14,8 v s .30,1 \mathrm{~g} / \mathrm{kg} \mathrm{ka})(\mathrm{P}<0,01)$ ja maitohappopitoisuus suurempi $(68,6$ vs. $55,4 \mathrm{~g} / \mathrm{kg} \mathrm{ka})(\mathrm{P}<0,01)$ kuin keskimäärin happorehuissa. Numeerinen ero maitohappopitoisuudessa ei ollut yhtä suuri kuin tuoreessa rehussa. Toisaalta sokeripitoisuudessa ero oli suurempi.

Painorehun ja happorehujen välillä ei ollut merkitseviä eroja VFA-pitoisuuksissa. Etikkahapon pitoisuus oli sama painorehussa ja muissa rehuissa. Painorehussa maitohapon osuus käymishapoista $(80,0)$ ja maitohappo/etikkahappo -suhde $(4,1)$ olivat kuitenkin suuremmat kuin happorehuissa $(77,0$ ja 3,4$)$ $(\mathrm{P}<0,01)$. Säilöntäajan lopussa painorehun etanolipitoisuus oli suurempi kuin happorehujen $(\mathrm{P}<0,01) \mathrm{ja}$ neutralointiasteen nosto lisäsi pitoisuutta (lin $\mathrm{P}<0,05)$.

Korjaamaton ammoniumtypen osuus oli painorehussa suurempi kuin rehuissa AF0-AF10, mutta pienempi kuin rehuissa AF20-AF40. Sen sijaan säilöntäaineessa lisätyn perusteella korjattu painorehun ammoniakkiluku oli kaikkia AF-rehuja suurempi $(\mathrm{P}<0,001)$.

Säilöntäaineen neutralointiasteen vaikutus esikuivatun rehun käymiseen oli selvästi lineaarisempi kuin tuoreessa rehussa. Sokeripitoisuus pieneni ja maitohappo- sekä etanolipitoisuudet suurenivat (lin $\mathrm{P}<0,05)$ neutraloinnin lisääntyessä. Numeerisesti $\mathrm{AF} 0$-rehun sokeripitoisuudesta $(31,5 \mathrm{~g} / \mathrm{kg} \mathrm{ka})$ poikkesivat kuitenkin vain $\operatorname{AF30}(22,4)$ ja $\mathrm{AF} 40(18,7)$. Maitohappopitoisuudessa selvempi ero AF0-rehuun verrattuna $(54,2 \mathrm{~g} / \mathrm{kg} \mathrm{ka})$ syntyi vain AF40-rehussa $(62,4)$. Kaiken kaikkiaan neutralointiasteen vaikutukset olivat suhteellisen vähäisiä.

Korjaamaton ammoniumtypen osuus suureni (lin $\mathrm{P}<0,001)$ ja korjattu pieneni $($ lin $\mathrm{P}<0,01)$ ammoniumformiaatin osuuden lisääntyessä säilöntäaineessa. Haihtuvista rasvahapoista voihapon pitoisuus väheni lineaarisesti (lin $\mathrm{P}<0,05)$ neutraloinnin lisääntyessä, mutta numeerisesti vaikutus oli hyvin pieni.

\section{Johtopäätökset}

Muurahaishapon osittainen neutralointi ei heikentänyt sen säilöntätehoa, kun käytettiin suositusten mukaista annostusta 5 1/t.

Tutkimuksessa saatiin esille neutraloinnin vaikutukset käymisprosessissa. Toisaalta, kun kaikki rehut, painorehu mukaan lukien, olivat säilönnälliseltä laadultaan hyviä, säilöntäaineiden vaikutuksesta virhekäymisen estämisessä ei voi tehdä johtopäätöksiä.

Puhtaaseen muurahaishappoon verrattuna säilöntäaineen neutralointi vaikutti tuoreen rehun käymisprosessiin vasta AF40-tasolla, jolloin rehun $\mathrm{pH}$ oli korkeampi ja maitohappokäyminen runsaampaa muihin happorehuihin verrattuna. Painorehuun verrattuna AF40:n maitohappokäyminen oli vähäisempää ja pH korkeampi.

Puhtaaseen muurahaishappoon verrattuna säilöntäaineen neutralointi vaikutti esikuivatun rehun käymisprosessiin AF30 ja AF40-tasoilla, jolloin rehun pH oli säilönnän alussa korkeampi ja käyminen runsaampaa varsinkin AF40 tasolla. Silti myös AF30 ja AF40 rajoittivat käymistä painorehuun verrattuna. Myös alemmat neutralointiasteet hidastuttivat $\mathrm{pH}: n$ laskua, mutta lopullinen $\mathrm{pH}$ vastasi AFOrehua.

\section{Kirjallisuus}

Jaakkola, S., Huhtanen, P. \& Kaunisto, V. 1993. VFA Proportions and microbial synthesis in the rumen of cattle receiving grass silage ensiled with different rates of formic acid. Proceedings of the $10^{\text {th }}$ International Conference on Silage Research, Dublin City University, Ireland, pp. 139-140. 
SUOMEN MAATALOUSTIETEELLISEN SEURAN TIEDOTE NRO 21

Taulukko 2. Tuoreiden säilörehujen koostumus. Typpipitoisuus ja ammonium N-pitoisuus on ilmoitettu sekä analysoituna että korjattuna säilöntäaineessa lisätyn perusteella.

\begin{tabular}{|c|c|c|c|c|c|c|c|c|c|c|c|c|c|c|}
\hline & $\begin{array}{l}\text { Kuiva- } \\
\text { aine }\end{array}$ & pH & $\begin{array}{l}\text { Maito- } \\
\text { happo }\end{array}$ & Sokeri & Etanoli & $\begin{array}{c}\text { Etikka- } \\
\text { happo }\end{array}$ & VFA yht. & $\begin{array}{l}\text { Muur. } \\
\text { happo }\end{array}$ & Typpi & $\begin{array}{l}\text { Typpi } \\
\text { korj }\end{array}$ & \multirow{2}{*}{\multicolumn{2}{|c|}{$\begin{array}{c}\mathrm{NH}_{3}-\mathrm{N} \mathrm{NH}_{3}-\mathrm{Nk} \\
\% \text { kok-N }\end{array}$}} & \multirow{2}{*}{$\begin{array}{c}\text { Kaasu } \\
\mathrm{ml} / \mathrm{g} \mathrm{ka}\end{array}$} & \multirow{2}{*}{$\begin{array}{c}\begin{array}{c}\text { Painon- } \\
\text { muutos }\end{array} \\
\mathrm{g}\end{array}$} \\
\hline & \multicolumn{2}{|l|}{$\mathrm{g} / \mathrm{kg}$} & \multicolumn{8}{|c|}{ g/kg ka } & & & & \\
\hline PR & 222 & 4,03 & 121,2 & 17,0 & 14,0 & 34,4 & 35,3 & 0,0 & 28,3 & 27,3 & 60,5 & 60,5 & 20,5 & 0,96 \\
\hline AFO & 221 & 4,07 & 71,1 & 25,1 & 14,8 & 24,6 & 25,0 & 12,0 & 27,8 & 27,8 & 28,5 & 28,5 & 17,5 & 0,83 \\
\hline AF5 & 221 & 4,11 & 73,0 & 22,5 & 15,0 & 32,3 & 33,2 & 10,3 & 27,7 & 27,4 & 53,8 & 43,4 & 20,7 & 0,96 \\
\hline AF10 & 220 & 4,00 & 65,8 & 27,4 & 8,2 & 24,1 & 24,4 & 15,9 & 28,9 & 28,3 & 35,3 & 14,6 & 16,1 & 0,79 \\
\hline AF20 & 223 & 4,04 & 71,2 & 26,0 & 15,9 & 24,5 & 24,8 & 15,6 & 28,8 & 27,6 & 48,4 & 6,9 & 16,8 & 0,86 \\
\hline AF30 & 225 & 4,08 & 71,0 & 26,8 & 15,3 & 24,2 & 24,4 & 15,1 & 29,8 & 28,0 & 63,5 & 3,7 & 16,3 & 0,89 \\
\hline AF40 & 219 & 4,16 & 90,8 & 21,3 & 17,3 & 32,5 & 34,0 & 9,7 & 28,9 & 26,5 & 94,7 & 11,2 & 21,4 & 1,06 \\
\hline SEM & 1,2 & 0,008 & 1,08 & 0,96 & 0,97 & 3,96 & 4,37 & 0,53 & 0,47 & 0,47 & 1,09 & 1,52 & 1,54 & 0,056 \\
\hline \multicolumn{15}{|c|}{ Tilastollinen merkitsevyys } \\
\hline PR vs. muut & & $* * *$ & $* * *$ & $* * *$ & & & & $* * *$ & & & $* * *$ & $* * *$ & & \\
\hline AF lin & & $* * *$ & $* * *$ & $*$ & $* *$ & & & $*$ & & & $* * *$ & $* * *$ & & $*$ \\
\hline AF quadr & & $* * *$ & $* * *$ & $* *$ & $*$ & & & $* * *$ & & & $* * *$ & $* * *$ & & \\
\hline AF cubic & $*$ & $*$ & $*$ & & $* *$ & & & & & & $*$ & & & \\
\hline AF quart & $*$ & & $* *$ & & $* *$ & & & & & & & & & \\
\hline
\end{tabular}

SEM = keskiarvon keskivirhe

Tilastollinen merkitsevyys: $* \mathrm{P}<0,05 ; * * \mathrm{P}<0,01 ; * * * \mathrm{P}<0,001$

AF lin, quadr, cubic, quart $=$ neutralointiasteen lineaarinen, toisen, kolmannen ja neljännen asteen vaikutus 
SUOMEN MAATALOUSTIETEELLISEN SEURAN TIEDOTE NRO 21

Taulukko 3. Esikuivattujen säilörehujen koostumus. Typpi ja ammonium N-pitoisuus on ilmoitettu sekä analysoituna että korjattuna säilöntäaineessa lisätyn perusteella.

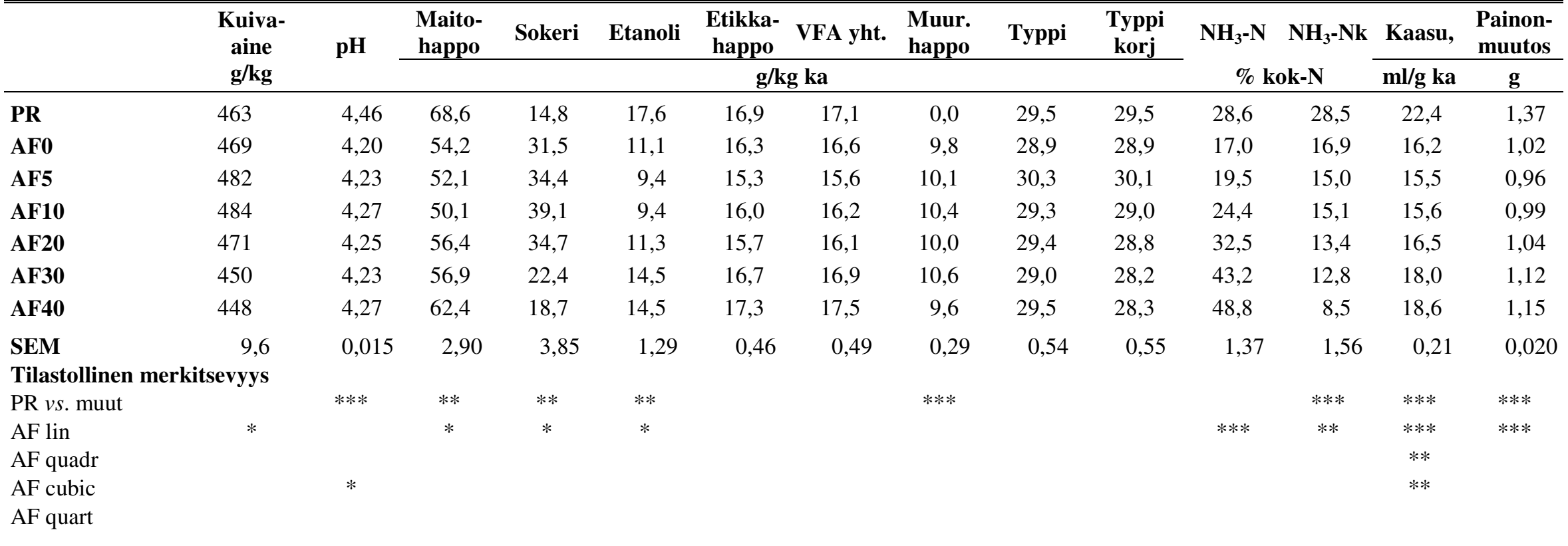

SEM = keskiarvon keskivirhe

Tilastollinen merkitsevyys: * $\mathrm{P}<0,05 ; * * \mathrm{P}<0,01 ; * * * \mathrm{P}<0,00$

AF lin, quadr, cubic, quart $=$ neutralointiasteen lineaarinen, toisen, kolmannen ja neljännen asteen vaikutus 

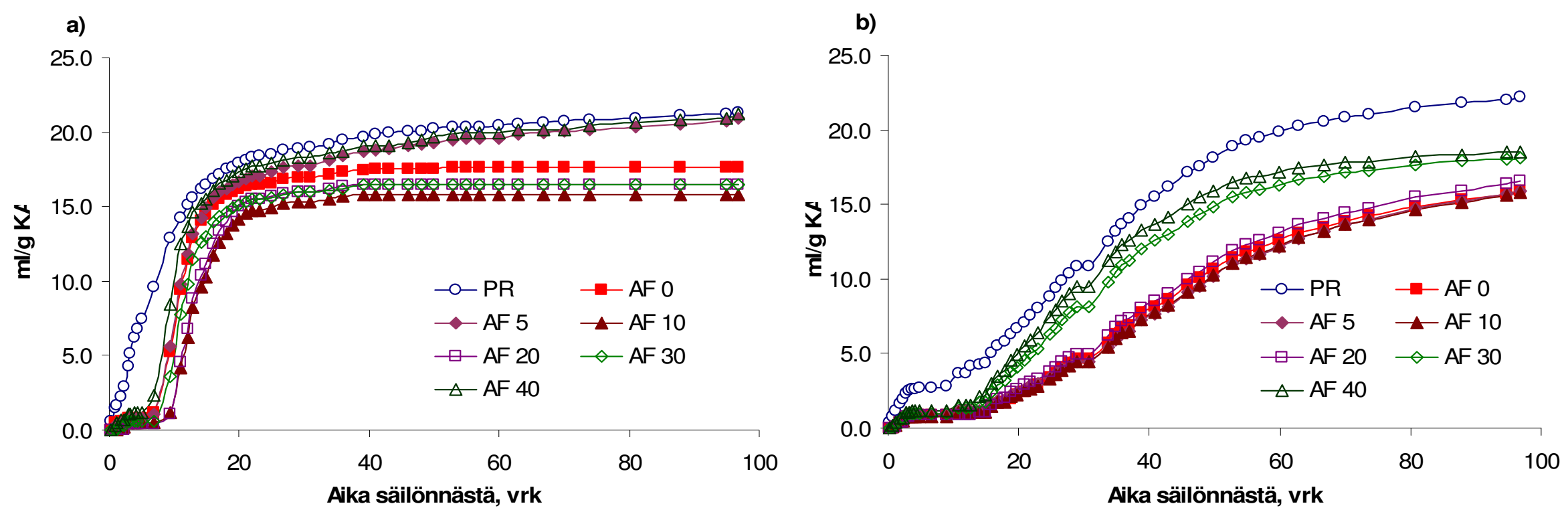

Kuvio 1. Säilönnän aikainen kaasunmuodostus a) Tuore, b) Esikuivattu.


Kuvio 2. Säilönnän aikainen muutos tuoreen ja esikuivatun rehun pH:ssa. 